\title{
PEMETAAN PARTISIPATIF POTENSI DESA (STUDI KASUS: DESA SELOPATAK, KECAMATAN TRAWAS, KABUPATEN MOJOKERTO
}

\author{
Hepi Hapsari, Agung Budi Cahyono \\ Jurusan Teknik Geomatika FTSP-ITS, Kampus ITS Sukolilo, Surabaya, 60111 \\ email : hepihapsari@gmail.com, agungbcahyo@yahoo.com
}

\begin{abstract}
Abstrak
Indonesia merupakan negeri yang besar baik dari segi luas wilayah, jumlah penduduk, sumberdaya alam dan budaya. Untuk membangun negeri Indonesia yang besar dan strategis tersebut, diperlukan perencanaan yang didukung data dan informasi spasial yang lengkap, up to date, andal serta dapat dipertanggungjawabkan. Undang-Undang Informasi Geospasial (UU IG) bertujuan untuk menjamin ketersediaan dan akses IG yang dapat dipertanggungjawabkan serta mewujudkan kebergunaan dan keberhasilgunaan IG melalui kerjasama, koordinasi, integrasi, dan sinkronisasi. UU ini mendorong penggunaan IG dalam pemerintahan dan kehidupan bermasyarakat dengan menggunakan referensi tunggal (single reference) yang mencakup Informasi Geospasial Dasar (IGD) dan Informasi Geospasial Tematik (IGT).

Pemetaan partsipatif adalah publik bersama-sama atau terlibat dalam proses pengumpulan data dan analisis terkait problem dan isu di sekitar mereka melalui identifikasi dan penggambaran fitur geospasial dengan menggunakan piranti dan teknologi pemetaan. Pemetaan partisipatif semakin memberi ruang yang lebar terhadap komunikasi dua arah antara pemerintah dan masyarakat, dan juga antarpemangku kepentingan pada daerah pengembangan. Pemetaan partisipatif adalah pemetaan yang dilakukan oleh kelompok masyarakat mengenai tempat/wilayah di mana mereka hidup. Karena masyarakat yang hidup dan bekerja di tempat itulah yang memiliki pengetahuan mendalam mengenai wilayahnya. Jadi, hanya mereka yang bisa membuat peta secara lengkap dan akurat mengenai sejarah, tata guna lahan, pandangan hidup, dan harapan masa depan. Manfaat pemetaan partisipatif bagi masyarakat adalah untuk meningkatkan kesadaran seluruh anggota masyarakat mengenai hak-hak mereka atas tanah dan sumber daya alam.Peta bisa digunakan sebagai media negosiasi dengan pihak lain, karena dengan peta tersebut menjadi jelaslah bagaimana wilayah itu dimanfaatkan oleh masyarakat dan siapa saja yang berhak atas wilayah itu.Proses pemetaan partisipatif menumbuhkan semangat untuk menggali pengetahuan lokal, sejarah asal-usul, sistem kelembagaan setempat, pranata hukum setempat, identifikasi sumber daya alam yang dimiliki, dan sebagainya.
\end{abstract}

Tujuan dalam kegiatan pengabdian masyarakat di Desa Selotapak, Mojokerto ini adalah sebagai pembuatan peta partisipatif Desa Selotapak, Mojokerto yang dijadikan sebagai dasar penataan ruang berdasarkan potensi yang ada. Masyarakat Desa Selotapak, Mojokerto dapat berperan serta dalam proses perencanaan, pemanfaatan, dan pengendalian pemanfaatan ruang wilayah desanya berdasarkan potensi yang ada.

Kata kunci: Pemetaan partisipatif, Desa Selotapak, Mojokerto, perencanaan kawasan pedesaan

\section{PENDAHULUAN}

\section{Latar Belakang}

Undang-Undang Informasi Geospasial (UU IG) bertujuan untuk menjamin ketersediaan dan akses IG yang dapat dipertanggungjawabkan serta mewujudkan kebergunaan dan keberhasilgunaan IG melalui kerjasama, koordinasi, integrasi, dan sinkronisasi. UU ini mendorong penggunaan IGdalam pemerintahan dan kehidupanbermasyarakat dengan menggunakan referensi tunggal (single reference) yang mencakup Informasi Geospasial Dasar (IGD) dan Informasi Geospasial Tematik
(IGT). Secara umum negara Indonesia dalam pembangunannyatidak lepas dari peraturan dan perundangan di Indonesia yaitu antara lain adalah sebagaimana diamanatkan amanat UUD 1945 Pasal 33 Ayat 3, 4 dan 5, pengelolaan sumberdaya alam memerlukan peta dan informasi geospasial untuk menunjukkan lokasi dan sebaran potensinya. Hal ini untuk menjalankan amanat UUD 1945 Pasal 25A, dan Pasal 30 Ayat 2. Setiap Warga Negara Indonesia berhak mencari, memperoleh, memiliki, menyimpan, mengolah, dan menyampaikan peta dan informasi geospasial untuk mengembangkan 
pribadi dan lingkungan sosialnya dengan menggunakan segala jenis saluran yang tersedia. Hal ini diamanatkan pada UUD 45 pasal 28F, bahwa agar setiap orang berhak mendapatkan manfaat yang optimal dari kemajuan ilmu dan teknologi informasi geospasial serta agar negara dapat maksimal memajukan ilmu dan teknologi informasi geospasial demi kemajuan peradaban serta kesejahteraan umat manusia.

Pemerintah sebagai fasilitator dengan menyusun NSPM (sesuai dgn hak dan kewajibannya -PP 69/96 sejauh mengikuti PP 10/2000). "Pemetaan partisipatif" merupakan metode alternatif dalam rangkapenyediaan informasi spasial. Dengan adanya perundangan-undangan yang mengatur, maka masyarakat desa dapat berpartisipasi dalam pembuatan peta di desa mereka sendiri. Karena selama ini peta menjadi acuan tata ruang dalam pelaksanaan pembangunan nasional. Masyarakat juga bisa membuat peta untuk kepentingan pembelajaran budaya lokal dan pewarisan pengetahuan bagi generasi selanjutnya, terutama yang berhubungan dengan sumber daya alam dan potensi yang ada di desanya.

Tujuan dalam kegiatan pengabdian masyarakat di Desa Selotapak, Mojokerto ini adalah sebagai pembuatan peta partisipatif Desa Selotapak, Mojokerto yang dijadikan sebagai dasar penataan ruang berdasarkan potensi yang ada. Masyarakat Desa Selotapak, Mojokerto dapat berperan serta dalam proses perencanaan, pemanfaatan, dan pengendalian pemanfaatan ruang wilayah desanya berdasarkan potensi yang ada.

\section{METODOLOGI PENELITIAN}

\section{Lokasi Penelitian}

Lokasidilakukan di Desa Selotapak, Kecamatan Trawas, Kabupaten Mojokerto, yang terdiri dari Dusun Jaten dan Dusun Selotapak.

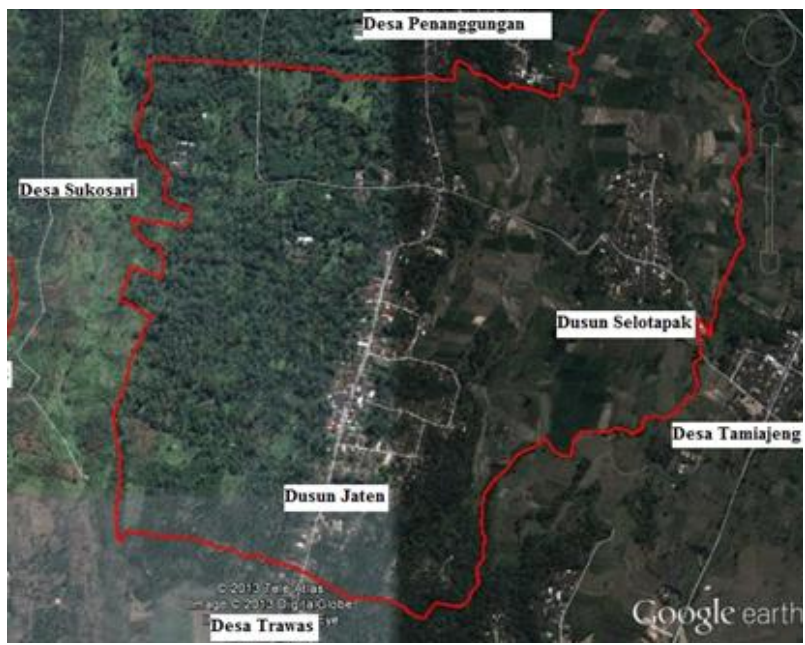

Gambar 1. Lokasi pengabdian

\section{Data Dan Peralatan}

- Data

Data yang digunakan dalam penelitian ini adalah:

1. Peta situasi Desa Selotapak Kecamatan Trawas, Mojokerto

2. Citra satelit Desa Selotapak, Kecamatan Trawas, Mojokerto

\section{- Peralatan}

Peralatan yang digunakan dalam penelitian ini adalah berupa perangkat keras yaitu Total Station, GPS Geodetic Dual Frequency TOPCON Hiper Pro, GPS navigasi, Rol Meter, Statif, Accumulator dan Kompas.

\section{HASIL DAN PEMBAHASAN}

\section{Rincian Tahapan Pekerjaan}

1. Tahap Perencanaan

Tahap perencanaan adalah tahapan pertama, di mana semua pekerjaan direncanakan. Adapun perencanaan yang kami lakukan adalah:

- PerencanaanPersebaran Titik/Pemilihan Lokasi Titik GCP

Jumlah total GCP adalah tujuh dengan rincian 1 GCP sentral, 1 di batas utara desa, 1 di batas barat desa, 2 di selatan desa, dan 2 di bagian timur desa.

- Perencanaan Metode Pengamatan Metode pengamatan yang direncanakan adalah metode Statik Singkat, dengan karakteristik baseline jaring. Metode ini 
hanya digunakan pada GCP utama tiap desa. Jadi terdapat empat titik yang membentuk jaring. Untuk pengamatan tiap desa menggunakan baseline Radial yang diikatkan pada GCP utama yang telah diamati menggunakan metode Jaring, dengan metode pengamatan Statik Singkat.

- Perencanaan Jadwal Pengamatan

\section{Tahap Pelaksanaan}

Di sini semua perencanaan dieksekusi menjadi pelaksanaan, yaitu:

- Pengecoran dan Pematokan GCP Desa Selotapak dan partipatif penduduk desa untuk mengidentifikasi dan marking potensi desa yang ada. Meliputi :

- Survei fasilitas umum desa

Pekerjaan ini dilakukan dengan melakukan survei tempat-tempat di desa Selotapak yang terdapat fasilitas umum seperti masjid, sekolah, kantor kepala desa, pemandian umum, PAUD, musholla, TPQ, Ponkesdes (Pos Pelayanan Kesehatan Desa), Bhabinkamtibmas (Bhayangkara Bina Keamanan dan Ketertiban Masyarakat), kantor PKK.

- Survei sumber mata air desa Selotapak Sumber air desa Selotapak : sumber towo, sumber nongko, sumber rawu, sumber cepoko, sumber kepundung, sumber ubalan, sumber gondang.

- Survei jalan-jalan dan potensi desa Selotapak

Nama jalan di desa Selotapak : jalan Yon Cipto dan jalan Penanggungan.

Di desa Selotapak terdapat tempattempat usaha mikro yang bisa dikembangkan, seperti : keripik telo, keripik singkong, keripik tempe, keripik pisang, keripik nangka, keripik ubi, usaha pallete kayu, usaha penggergajian kayu, usaha mebel, usaha material dan pengelasan, usaha peternakan ayam

- Survei organisasi-organisasi desa Selotapak

Di desa Selotapak terdapat organisasi : LPM, BPD, Karang Taruna, PKK.

- Survei struktur pemerintah dan demografi desa
- Pengukuran Titik GCP

Dengan mengubah metode menjadi metode Radial.Pengukuran titik GCP di Desa Selotapak dilakukan dengan metode radial pada 7 titik GCP yang telah tersebar sebelumnya.

- Pengukuran Titik Ikat Untuk Total Station. Pengukuran titik ikat ini sebenanya sudah dilakukan pada pengukuran GCP, dilakukan dengan metode radial pada 8 titik yang telah ditentukan sebelumnya.

3. Tahap Pengolahan dan Analisis Data

- Pada survei dengan GPS, pemrosesan data GPS untuk menentukan koordinat dari titik-titik dalam jaringan umumnya akan mencakup tiga tahapan utama perhitungan, yaitu pengolahan data dari setiap baseline dalam jaringan, perataan jaringan yang melibatkan semua baseline untuk menentukan koordinat dari titik-titik dalam jaringan, dan transformasi koordinat titik-titik tersebut dari datum WGS84 ke datum yang diperlukan oleh pengguna. Pengolahan data dari setiap baseline GPS pada dasarnya adalah bertujuan menentukan nilai estimasi vektor baseline atau koordinat relatif (dX, dY, dZ).

- Pengukuran BM Utama tiap desa dengan metode Jaring mengalami kendala. Sehingga perlu dilakukan pengukuran ulang.

\section{Data Monografi Desa}

Desa

Kecamatan

Kabupaten

Propinsi
Selotapak

Trawas

Mojokerto

Jawa Timur

\section{Bidang PemerintahanUmum}

$\begin{array}{ll}\text { Luas Desa } & : 186,233 \mathrm{Ha} \\ \text { Batas Wilayah } & \\ \text { Sebelah Utara } & \text { :Desa Penanggungan } \\ \text { Sebelah Selatan } & \text { :Desa Trawas } \\ \text { Sebelah Barat } & \text { :Desa Sukosari } \\ \text { Sebelah Timur } & \text { :Desa Tamiajeng }\end{array}$

\section{Kondisi Geografis}

Ketinggian tanah dari permukaan laut : $700 \mathrm{M}$ Banyaknya curah hujan

: $1.271 \mathrm{~mm}$ 
Suhu udara rata-rata

$: 24^{\circ} \mathrm{C}$

Jarak dari Pusat Pemerintahan Kecamatan: 3km Jarak dari Ibukota Kabupaten

: $42 \mathrm{~km}$

Jarak dari Ibukota Propinsi

: $80 \mathrm{~km}$

\section{Potensi}

- Nama

$$
\begin{aligned}
& \text { : Usaha Pallete Kayu } \\
& \text { : Terletak di depan PAUD } \\
& \text { Darussalam }
\end{aligned}
$$

Deskripsi : Hasil penggergajian kayu dikirim ke pabrik di Mojokerto, Pemiliknya adalah Pak Gunawan, jumlah karyawan 8 orang. Selain untuk pallete kayu, sisa serbuk kayunya dapat digunakan untuk bahan baku pembuatan kertas serta media untuk penanaman anggrek.

Koordinat : $0676126 ; 9153771$

Keterangan : Elevasi $646 \mathrm{~m}$

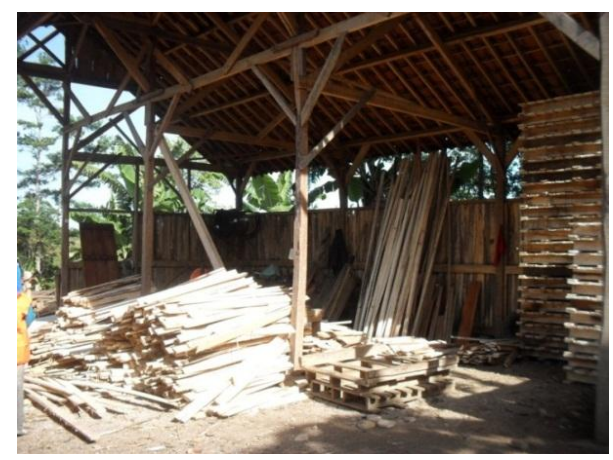

Gambar 2. Usaha pallete kayu

- Nama : Usaha Daur Ulang

Keadaan : Terletak di dekat PAUD

Darussalam

Deskripsi : Pemilik usaha ini adalah Pak Supono, jumlah karyawan tetap tidak ada karena karyawan tidak terikat, telah berdiri \pm 10 tahun.

Koordinat : $0676131 ; 9153803$

Keterangan : Elevasi $635 \mathrm{~m}$

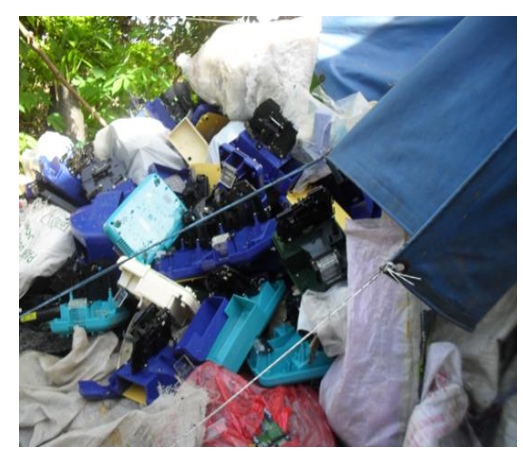

Gambar 3. Usaha daur ulang
- Nama : Usaha Packing Plastik

Lokasi : Terletak di depan PAUD Darussalam

Deskripsi : Merupakan jasa packing, pemiliknya adalah Pak Naseb, jumlah karyawan adalah 9 karyawan, sudah berdiri selama 10 tahun.

Narasumber : Ibu Tatik

Koordinat : 0675477;9153569

Keterangan : Elevasi $686 \mathrm{~m}$

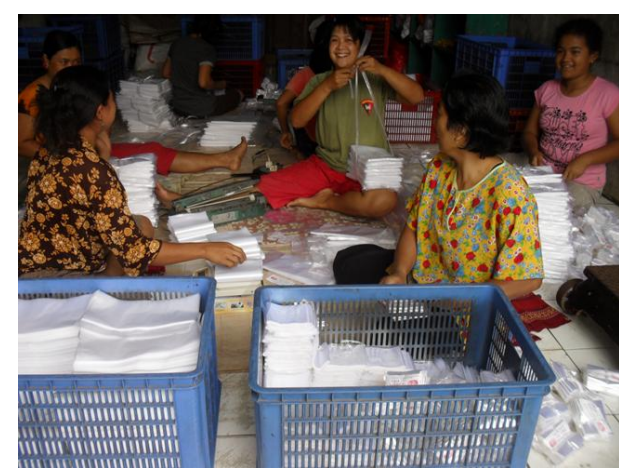

Gambar 4. Packing plastik

- Nama : Budidaya Anggrek

Keadaan : Letaknya di Kantor Desa Selotapak.

Deskripsi : Pemiliknya adalah Bapak Slamet (Kades)

Toponimi : Taman Anggrek ini adalah hobi pak Kades yang ternyata bisa menjadi potensi usaha karena sudah banyak dikenal warga. Di taman anggrek ini terdapat anggrek bulan, anggrek hitam.

Narasumber : Pak Kades

Koordinat : $0675675 ; 9153803$

Keterangan : Elevasi $669 \mathrm{~m}$

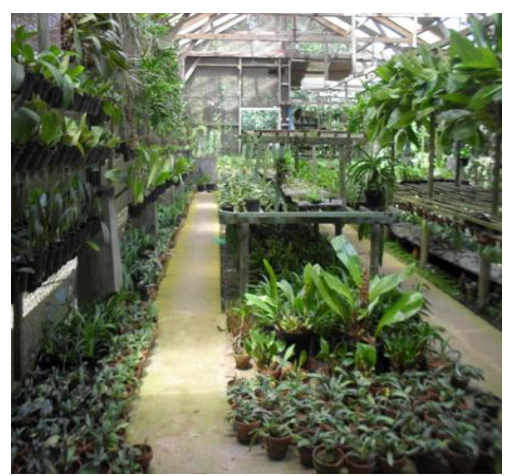

Gambar 5. Budidaya anggrek 


\section{- Nama : Perkebunan Salak \\ Keadaan : Cukup luas \\ Deskripsi : Letaknya tepat di belakang \\ Pohon Kramat \\ Koordinat : 0675620;9154069 \\ Keterangan : $657 \mathrm{~m}$}

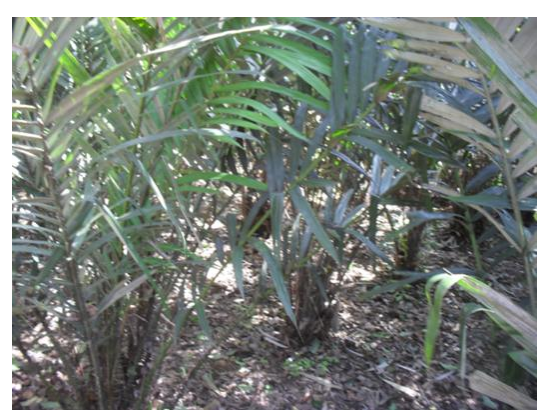

Gambar 6. Perkebunan salak

- Nama : Sumber Air Nongko

Keadaan : Sumber airnya tidak terlihat karena tertutup oleh rumput - rumput.

Deskripsi : Terletak di tengah - tengah sawah. Berfungsi untuk irigasi sawah

Toponimi : Dinamakan sumber nongko karena terletak di sebelah pohon nangka

Narasumber : Pak Slamet

Koordinat : $675795 ; 9153802$

Keterangan : Elevasi $641 \mathrm{~m}$

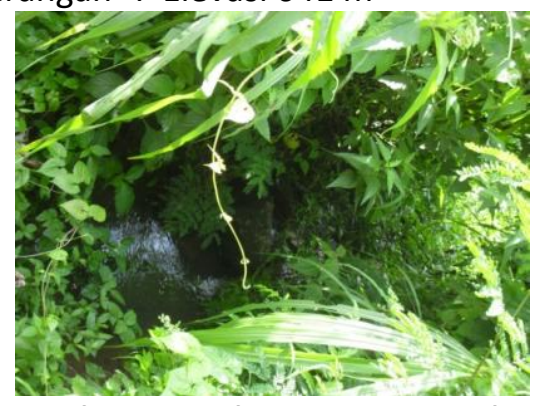

Gambar 7. Sumber mata air nongko

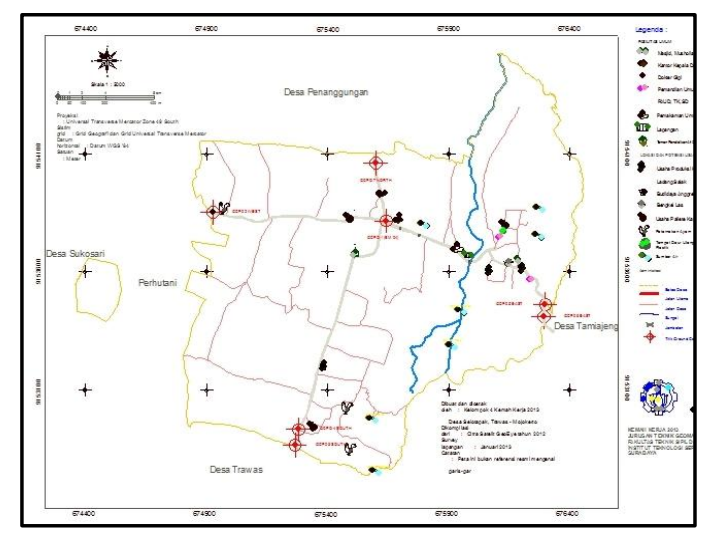

Gambar 8. Peta Potensi Desa Selotapak, Trawas, Mojokerto

\section{PENUTUP}

Adapun kesimpulan yang dapat di ambil dari penelitian ini adalah sebagai berikut :

1. Pengukuran kerangka kontrol horisontal (KKH) diperlukan untuk menghitung koordinat horisontal ( $X$ dan $Y$ ) yang nantinya akan digunakan untuk menentukan posisi titik-titik detil.

2. Kesalahan penutup sudut kerangka kontrolhorizontal adalah $-000^{\prime} 29,9^{\prime \prime}$, toleransinya $5^{\prime \prime} \mathrm{v}=5^{\prime \prime} \sqrt{20}=$ 22,36067977",sehingga tidak masuk toleransi.

3. Kesalahan linier relatif poligon adalah 0.001 . Toleransi kesalahannya $1: 6000$, sehingga memenuhi toleransi.

4. Toleransi pengukuran kerangka kontrol vertical adalah 11,05621997 mm. Adapun kesalahan dari pengukuran kerangka kontrol vertical adalah $-1.85607 \mathrm{~m}$, sehingga tidak memenuhi toleransi.

5. Potensi usaha Desa Selotapak meliputi usaha peternakan ayam, perkebunan salak, penggergajian kayu, budidaya anggrek, dan usaha lain yang merupakan keterampilan warga. Sedangkan potensi wisata berupa sumber mata air.

\section{DAFTAR PUSTAKA}

Hartanto, (2010), Pemetaan Partisipatif, http://hartanto.wordpress.com/2010/01/ 25/pemetaanpartisipatif-bersamasijampang/diakses tanggal 08-01-2014 jam 13.55

Hidayat,(2005), Seri Panduan Pemetaan Partisipatif No. 2 - Mengenalkan Pemetaan Partisipatif,Garis Pergerakan, Bandung. 